\title{
(- OPEN ACCESS \\ Survival of very preterm infants admitted to neonatal care in England 2008-2014: time trends and regional variation
}

\author{
Shalini Santhakumaran, ${ }^{1,2}$ Yevgeniy Statnikov ${ }^{1,2}$ Daniel Gray, ${ }^{1,3}$ Cheryl Battersby, ${ }^{1,2}$ \\ Deborah Ashby, ${ }^{2}$ Neena Modi, ${ }^{1,2}$ on behalf of the Medicines for Neonates Investigator \\ Group
}

- Additional material is published online only. To view please visit the journal online (http://dx.doi.org/10.1136/ archdischild-2017-312748).

${ }^{1}$ Section of Neonatal Medicine, Department of Medicine, Imperial College London, London, UK

${ }^{2}$ Imperial Clinical Trials Unit, School of Public Health, Imperial College London, London, UK ${ }^{3}$ Royal College of Paediatrics and Child Health, National Neonatal Audit Programme, London, UK

\section{Correspondence to}

Professor Neena Modi; n.modi@ imperial.ac.uk

Received 20 January 2017 Revised 7 June 2017 Accepted 12 June 2017 Published Online First 7 September 2017
Check for updates

To cite: Santhakumaran $S$, Statnikov Y, Gray D, et al. Arch Dis Child Fetal Neonatal Ed 2018;103:F208-F215.

\section{ABSTRACT \\ Objective To analyse survival trends and regional} variation for very preterm infants admitted to neonatal care.

Setting All neonatal units in England.

Patients Infants born at $22^{+0}-31^{+6}$

weeks $^{\text {+days }}$ gestational age (GA) over 2008-2014 and admitted to neonatal care; published data for admitted infants $22^{+0}-25^{+6}$ weeks $^{+ \text {days }} \mathrm{GA}$ in 1995 and 2006, and for live births at $22^{+0}-31^{+6}$ weeks $^{\text {+days }} \mathrm{GA}$ in 2013.

Methods We obtained data from the National Neonatal Research Database. We used logistic regression to model survival probability with birth weight, GA, sex, antenatal steroid exposure and multiple birth included in the risk adjustment model and calculated annualpercentage change (APC) for trends using joinpoint regression. We evaluated survival over a 20 -year period for infants $<26$ weeks' GA using additional published data from the EPICure studies.

Results We identified 50112 eligible infants. There was an increase in survival over 2008-2014 (2008: 88.0\%; 2014: 91.3\%; adjusted APC 0.46\% $(95 \% \mathrm{Cl}$ 0.30 to 0.62$) p<0.001)$. The greatest improvement was at $22^{+0}-23^{+6}$ weeks (APC $6.03 \%(95 \% \mathrm{Cl} 2.47$ to 3.53$)$ $\mathrm{p}=0.002)$. Improvement largely occurred in London and South of England (APC: London 1.26\% (95\% Cl 0.60 to 1.96); South of England $1.09 \%(95 \% \mathrm{Cl} 0.36$ to 1.82$)$; Midlands and East of England $0.15 \%(95 \% \mathrm{Cl}-0.56$ to 0.86$) ;$ and North of England $0.26 \%(95 \% \mathrm{Cl}-0.54$ to 1.07)). Survival at the earliest gestations improved at a similar rate over $1995-2014\left(22^{+0}-25^{+6}\right.$ weeks, APC $2.73 \%(95 \% \mathrm{Cl} 2.35$ to 3.12$)$, p value for change $=0.25)$. Conclusions Continued national improvement in the survival of very preterm admissions masks important regional variation. Timely assessment of preterm survival is feasible using electronic records.

\section{INTRODUCTION}

Preterm birth is the primary cause of neonatal death worldwide and carries lifelong risks to health. ${ }^{12}$ Population, as opposed to hospital-based data, is essential to obtain an unbiased picture of survival, but undertaking such studies can be challenging and expensive. ${ }^{3}$ National data are also required to assess regional variation, a necessary step to identifying areas for improvement and reducing health inequalities.

The National Neonatal Research Database (NNRD) is a repository of a predefined set of

\section{What is already known on this topic?}

- The EPICure studies found survival of extremely preterm infants admitted to neonatal care in England to improve from 1995 to 2006.

- We identified no nationwide assessment of preterm survival following neonatal care since that time. This is likely to reflect the difficulties and costs of large-scale data collection.

\section{What this study adds?}

- Our study shows that survival of preterm infants admitted to neonatal care has continued to improve, particularly for infants of the lowest gestations. However we also identified regional variation that is not explained by patient characteristics.

- Improvements have not been consistent across the country, warranting further investigation into the reasons for variation.

- As large, population-based studies are required to detect unusual variation in patient outcomes, electronic patient records provide opportunity to conduct such studies efficiently.

variables (the Neonatal Data Set; National Health Service (NHS) Information Standard SCCI1595), extracted quarterly from clinician-entered, pointof-care electronic patient records (EPR) for all infants admitted to neonatal units in England, Wales and Scotland. ${ }^{4}$ Data are cleaned (eg, assessed for duplicates and inconsistencies), potential errors are checked with clinical teams and multiple episodes merged to create a single patient record.

We evaluated trends in survival for infants born $22^{+0}-31^{+6}$ weeks' gestation and admitted to neonatal units in England 2008-2014. We assessed regional variation and relationship with socioeconomic deprivation. We examined survival trends over a 20-year period for those born at the earliest gestations by including previously published data. The secondary aims were to examine 28-day survival and postnatal age at death and develop a statistical model to predict survival. 


\section{METHODS}

We extracted NNRD data for infants born January 2008December 2014 from $22^{+0}-31^{+6}$ weeks $^{+ \text {days }}$ gestational age (GA) and admitted to a neonatal unit in England (data from Scotland and Wales were unavailable in 2008). The NNRD is approved by the National Research Ethics Service (16/LO/1093) and the Caldicott Guardians of contributing NHS Trusts. Approval is held from the Confidentiality Advisory Group of the Health Research Authority to hold NHS numbers for linkage (ECC8-05(f)/2010).

Data comprised GA (the best obstetric estimate, initially based on last menstrual period and modified by antenatal ultrasound), birth weight (BW), singleton/multiple pregnancy, administration of antenatal steroids, vaginal/caesarean delivery, maternal age, maternal ethnicity, smoking during pregnancy and Index of Multiple Deprivation (IMD) 2010 quintile based on lower super output area (LSOA) rank. ${ }^{5}$ We identified small-for-gestational age infants (BW $<10$ th centile for gestation), calculated BW SD score (UK-WHO preterm growth reference ${ }^{6}$ ), and excluded infants with BW greater than 4SD from the gestation and sex-specific mean as we considered these potentially erroneous. Outcomes were determined from discharge data.

To reduce missing data we linked the NNRD to UK Office of National Statistics-Hospital Episode Statistics (ONS-HES) data. ONS-HES data were used for 28-day survival only as we could not ascertain if death occurred in neonatal care. Data extraction and linkage were carried out using SAS V.9.3.

\section{Statistical analysis}

We estimated time trends for survival to discharge and 28 days using joinpoint regression. ${ }^{78}$ We used joinpoint regression to enable detection of any changes in survival trends. Joinpoint regression allows the number and location of the change points to be unknown and determines which change points, if any, fit the data best. The minimum and maximum number of joinpoints that could be selected was 0 and 5, respectively. We log-transformed rates; hence, trends are presented as annual percentage change (APC), the annual rate of change of the survival rate. We directly standardised survival rates for risk of death, ${ }^{9}{ }^{10}$ grouping infants into 10 risk categories, each with an equal number of predicted deaths. The risk of death was calculated using logistic regression, including established clinical risk factors (GA, BW, sex, singleton/multiple pregnancy, any antenatal steroids (no/ yes)). ${ }^{11}$ Online supplementary file 1 material shows the full methods including assessment of model fit.

We checked for seasonality by varying the autocorrelation parameter. As the number of neonatal units contributing data increased over time, we analysed complete neonatal networks as a sensitivity analysis. We tested for differences in postnatal age at death using quantile regression.

We restricted the regional analysis to 2011 onwards in view of the possibility that lower population coverage in earlier years might bias regional estimates. Infants were assigned to one of the four regions (London, Midlands and East of England, North of England and South of England) based on mothers' residence. We calculated crude and standardised rates of survival to discharge and trends in crude survival; standardised trends by region were not calculated due to low numbers. We calculated crude and standardised rates of survival to discharge for the highest and lowest IMD quintile and computed the risk difference (RD). We added region (categorical) and IMD decile (continuous) to the risk adjustment model to test for residual regional variation.

We compared NNRD data with published data for England. First we used joinpoint regression to compare recent trends in the NNRD data (2008-2014) with previous estimates from the EPICure studies $^{12}{ }^{13}$ (1995 and 2006). EPICure $199^{12}$ involved all deliveries at $20^{+0}-25^{+6}$ weeks $^{+ \text {days }}$ GA in March-December 1995 in every maternity unit in the UK and Ireland. EPICure $2^{13}$ provided information on all babies born $20^{+0}-25^{+6}$ weeks ${ }^{+ \text {days }}$ GA in England in 2006. Only infants admitted to neonatal care in England were included.

Second, we compared the number of infants at each GA week by 28 -day survival status and region of mother's residence in the NNRD (denominator: neonatal unit admissions) with published ONS data ${ }^{14}$ (denominator: live births) for infants born at $22^{+0}-31^{+6}$ weeks $^{+ \text {days }}$ GA. Data were compared for 2013 due to availability of England-only ONS data.

\section{RESULTS}

\section{Study population}

Data were available for $71 \%$ of neonatal units in England for $2008,80 \%$ in $2009,86 \%$ in $2010,97 \%$ in $2011,99 \%$ in 2012 and $100 \%$ in 2013 and 2014. There were 50467 infants born over $2008-2014$ at $22^{+0}-31^{+6}$ weeks GA who were admitted to a neonatal unit in England. We excluded 38 babies with implausible BW for GA, and 317 because BW, sex or multiple birth status was missing, leaving 50112 infants in the study cohort. Population characteristics were broadly similar across all 7 years (table 1), although some differences were statistically significant. The 20\% most deprived LSOA contributed over 30\% of the study population, while the $20 \%$ least deprived LSOA contributed $13 \%$.

\section{Survival to discharge from 2008 to 2014}

Of the 48422 admitted infants for whom outcomes were known, $43444(89.7 \%)$ survived to discharge over the whole period. Table 2 shows the associations between survival and infant characteristics. There was an increase in the percentage of admitted infants who survived to discharge from $88.0 \%$ in 2008 to $91.3 \%$ in 2014. Survival increased with GA from $17.9 \%$ for $22^{+0}$ to $22^{+6}$ weeks to $98.1 \%$ for $31^{+0}-31^{+6}$ weeks. Crude survival rates were lower for boys, vaginal delivery and infants whose mothers were younger, did not receive antenatal steroids, smoked and came from more deprived areas.

The APC for crude survival was $0.51 \%$ (95\% CI 0.35 to 0.67 , $\mathrm{p}<0.001$ ), and after standardisation for risk of death, $0.46 \%$ (95\% CI 0.30 to $0.62, \mathrm{p}<0.001$ ). Results were similar for all sensitivity analyses.

\section{Trends in survival to discharge by GA}

Figure 1 shows the joinpoint regression analysis for survival to discharge by GA group. Improvements were less marked with increasing GA $\left(22^{+0}\right.$ to $23^{+6}$ weeks: APC 6.03\% (95\% CI 2.47 to 3.53$), \mathrm{p}=0.002 ; 30^{+0}$ to $31^{+6}$ weeks APC $0.01 \%(95 \% \mathrm{CI}$ -0.08 to 0.09$), \mathrm{p}=0.9$ ).

\section{Survival to 28 days from 2008 to 2014}

Fifty additional deaths were identified by linkage with ONS-HES, of which 20 were within 28 days. There was an increase in the percentage of infants who survived to 28 days from $91.4 \%$ in 2008 to $93.5 \%$ in 2014 . Survival improved with GA $\left(48.4 \%\right.$ at $22^{+0}$ to $23^{+6}$ weeks to $98.2 \%$ at $30^{+0}$ to $31^{+6}$ weeks). The APC for crude 28 -day survival and after standardisation for risk of death were similar (crude: $0.30 \%(95 \% \mathrm{CI}$ 0.15 to 0.45$), \mathrm{p}<0.001$; after standardisation: $0.27 \%(95 \% \mathrm{CI}$ 0.11 to 0.44$), p=0.002)$. The results were also similar when only neonatal networks where all hospitals contributed data for the 


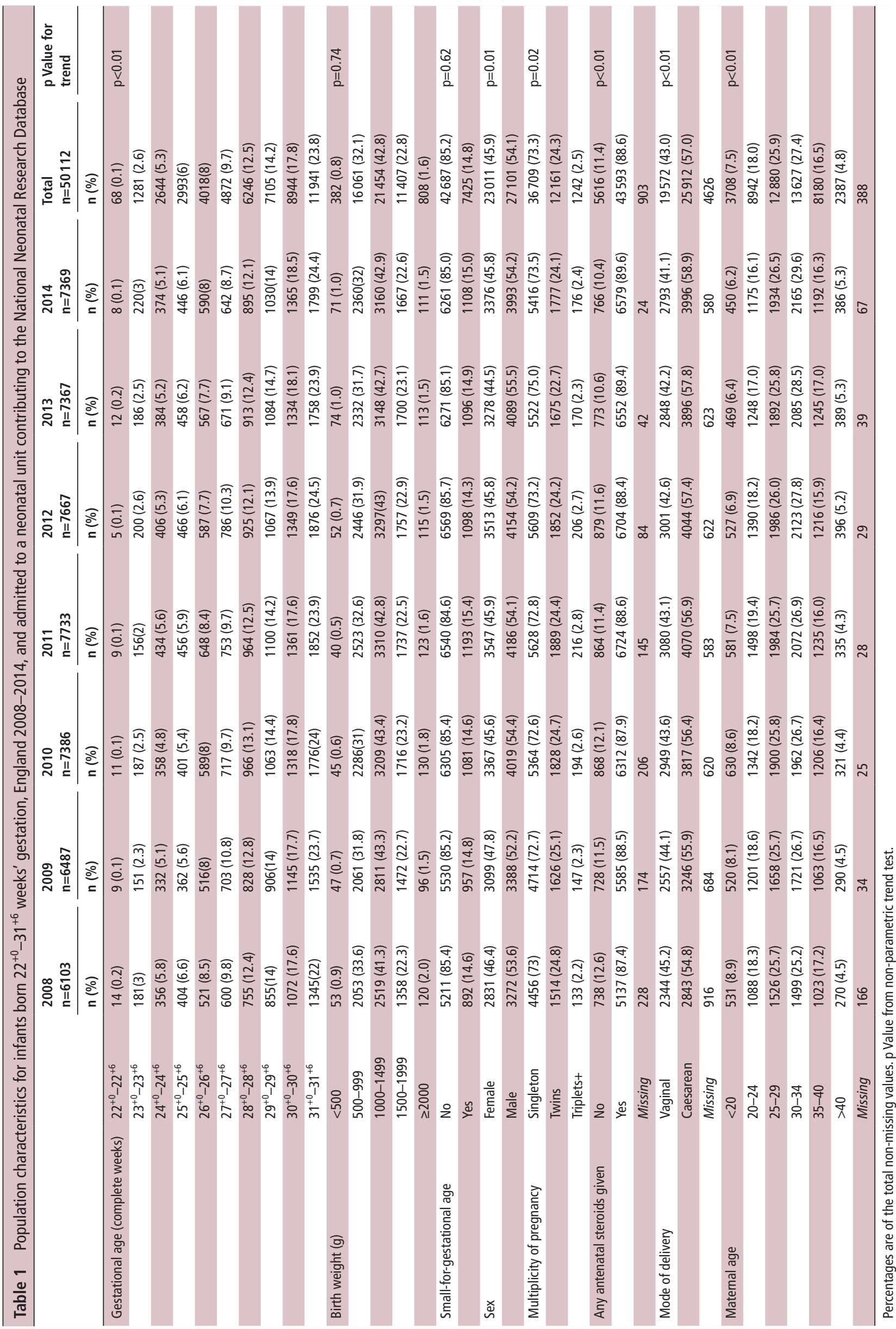


Table 2 Survival by population characteristics for infants born $22^{+0}-31^{+6}$ weeks' gestation, England 2008-2014, and admitted to a neonatal unit contributing to the National Neonatal Research Database

\begin{tabular}{|c|c|c|c|c|c|c|c|c|c|}
\hline \multirow{3}{*}{ Gestational (age weeks ${ }^{\text {+days }}$ ) } & & \multicolumn{2}{|c|}{ Survived to discharge } & \multirow[t]{2}{*}{ Missing } & \multirow[t]{2}{*}{$\mathrm{p}$ Value } & \multicolumn{2}{|c|}{ Survived to 28 days } & \multirow[t]{2}{*}{ Missing } & \multirow[t]{2}{*}{$\mathrm{p}$ Value } \\
\hline & & $\mathrm{n}$ & $\%(95 \% \mathrm{Cl})$ & & & $\mathrm{n}$ & $\%(95 \% \mathrm{Cl})$ & & \\
\hline & $22^{+0}-22^{+6}$ & 12 & 17.9 (8.7 to 27.2 ) & 1 & & 17 & 25.4 (14.9 to 35.9$)$ & 1 & \\
\hline & $23^{+0}-23^{+6}$ & 440 & 35.9 (33.2 to 38.6$)$ & 56 & & 629 & 49.6 (46.8 to 52.3 ) & 12 & \\
\hline & $24^{+0}-24^{+6}$ & 1464 & 58.6 (56.6 to 60.5 ) & 144 & & 1819 & 69.6 (67.8 to 71.4$)$ & 31 & \\
\hline & $25^{+0}-25^{+6}$ & 2091 & 74 (72.4 to 75.6$)$ & 167 & & 2421 & 81.7 (80.3 to 83 ) & 28 & \\
\hline & $26^{+0}-26^{+6}$ & 3199 & 83.4 (82.3 to 84.6 ) & 184 & $p<0.001$ & 3517 & 88.2 (87.2 to 89.2$)$ & 30 & $\mathrm{p}<0.001$ \\
\hline & $27^{+0}-27^{+6}$ & 4125 & 88.4 (87.5 to 89.4 ) & 208 & & 4426 & 91.9 (91.2 to 92.7$)$ & 57 & \\
\hline & $28^{+0}-28^{+6}$ & 5556 & 92.4 (91.7 to 93) & 231 & & 5839 & 94.5 (93.9 to 95.1 ) & 68 & \\
\hline & $29^{+0}-29^{+6}$ & 6599 & 95.7 (95.3 to 96.2 ) & 212 & & 6770 & 96.6 (96.2 to 97$)$ & 95 & \\
\hline & $30^{+0}-30^{+6}$ & 8491 & 97.5 (97.1 to 97.8$)$ & 232 & & 8621 & 97.8 (97.5 to 98.1$)$ & 128 & \\
\hline & $31^{+0}-31^{+6}$ & 11467 & 98.1 (97.9 to 98.4 ) & 255 & & 11603 & 98.4 (98.2 to 98.7 ) & 153 & \\
\hline \multirow[t]{5}{*}{ Birth weight (g) } & $<500$ & 127 & 34.8 (29.9 to 39.7 ) & 17 & & 192 & 50.7 (45.6 to 55.7 ) & 3 & \\
\hline & 500-999 & 11748 & 76.8 (76.2 to 77.5$)$ & 772 & & 13256 & 83.4 (82.8 to 84$)$ & 167 & \\
\hline & 1000-1499 & 19918 & 95.6 (95.3 to 95.9$)$ & 613 & $\mathrm{p}<0.001$ & 20431 & 96.4 (96.1 to 96.6$)$ & 259 & $\mathrm{p}<0.001$ \\
\hline & 1500-1999 & 10913 & 97.9 (97.7 to 98.2$)$ & 262 & & 11031 & 98.1 (97.8 to 98.3 ) & 158 & \\
\hline & $\geq 2000$ & 738 & 94.4 (92.8 to 96$)$ & 26 & & 752 & 94.9 (93.4 to 96.5$)$ & 16 & \\
\hline \multirow[t]{2}{*}{ Small-for-gestational age } & No & 37309 & 90.4 (90.1 to 90.7 ) & 1406 & $p<0.001$ & 38985 & 92.5 (92.2 to 92.7 ) & 538 & $\mathrm{p}<0.001$ \\
\hline & Yes & 6135 & 85.9 (85.1 to 86.7 ) & 284 & & 6677 & 90.7 (90.1 to 91.4 ) & 65 & \\
\hline \multirow[t]{2}{*}{ Sex } & Girls & 20190 & 90.6 (90.2 to 91$)$ & 732 & $p<0.001$ & 21090 & 92.8 (92.5 to 93.1 ) & 284 & $\mathrm{p}<0.001$ \\
\hline & Boys & 23254 & 88.9 (88.6 to 89.3$)$ & 958 & & 24572 & 91.7 (91.4 to 92.1 ) & 319 & \\
\hline \multirow[t]{3}{*}{ Multiplicity of pregnancy } & Singleton & 31845 & 89.7 (89.4 to 90.1$)$ & 1225 & $p<0.001$ & 33506 & 92.3 (92 to 92.6$)$ & 417 & $\mathrm{p}<0.001$ \\
\hline & Twins & 10472 & 89.3 (88.7 to 89.9 ) & 433 & & 10992 & 91.7 (91.2 to 92.2 ) & 172 & \\
\hline & Triplets+ & 1127 & 93.1 (91.7 to 94.6 ) & 32 & & 1164 & 94.8 (93.5 to 96$)$ & 14 & \\
\hline \multirow[t]{2}{*}{ Any antenatal steroids given } & No & 4421 & 82.1 (81.1 to 83.2 ) & 233 & $p<0.001$ & 4711 & 85 (84 to 85.9 ) & 72 & $\mathrm{p}<0.001$ \\
\hline & Yes & 38327 & 90.8 (90.5 to 91) & 1369 & & 40196 & 93.2 (93 to 93.5$)$ & 485 & \\
\hline \multirow[t]{2}{*}{ Mode of delivery } & Vaginal & 16346 & 85.9 (85.4 to 86.4 ) & 546 & $p<0.001$ & 17275 & 82.1 (81.1 to 83.2 ) & 190 & $p<0.001$ \\
\hline & Caesarean & 23473 & 93 (92.7 to 93.3 ) & 665 & & 24367 & 90.8 (90.5 to 91$)$ & 227 & \\
\hline \multirow[t]{6}{*}{ Maternal age } & $<20$ & 3143 & 88.3 (87.2 to 89.3 ) & 147 & $p<0.001$ & 3326 & 90.9 (90 to 91.9$)$ & 51 & $p<0.001$ \\
\hline & $20-24$ & 7639 & 88.5 (87.8 to 89.1$)$ & 308 & & 8063 & 91.3 (90.7 to 91.9 ) & 108 & \\
\hline & $25-29$ & 11268 & 90.3 (89.7 to 90.8 ) & 395 & & 11821 & 92.7 (92.2 to 93.1$)$ & 122 & \\
\hline & $30-34$ & 11890 & 90 (89.5 to 90.5$)$ & 421 & & 12460 & 92.5 (92.1 to 92.9 ) & 157 & \\
\hline & $35-40$ & 7171 & 90.4 (89.7 to 91$)$ & 246 & & 7505 & 92.8 (92.2 to 93.3$)$ & 89 & \\
\hline & $>40$ & 2105 & 90.7 (89.6 to 91.9$)$ & 67 & & 2198 & 93 (91.9 to 94) & 23 & \\
\hline
\end{tabular}

Percentages exclude missing. $\mathrm{p}$ Value from $\mathrm{X}^{2}$ tests.

whole period were examined (crude APC $0.35 \%$ (95\% CI 0.19 to 0.52$)$; adjusted APC $0.30 \%$ (95\% CI 0.14 to 0.47$)$ ).

\section{Postnatal age at death from 2008 to 2014}

Twenty-four per cent of deaths occurred within 24 hours, $28 \%$ between 25 hours and 7 days, $26 \%$ between 8 days and 28 days, and $23 \%$ beyond 28 days. The 75 th percentile for postnatal age at death fell from 27.2 days in 2008 to 20.8 days in 2013 but rose to 24.3 days in 2014 (estimated average annual decrease 2008-2014, 0.92 days $(95 \%$ CI 0.2 to 1.7$) \mathrm{p}=0.02)$; there was no evidence of a change in the median and 25 th percentile.

\section{Variation by region and IMD quintile using data from 2011 onwards}

Crude survival varied from $89.3 \%$ (95\% CI 88.6 to 89.9 ) in the Midlands and East of England to 91.1\% (95\% CI 90.3 to 91.8) in London; after standardisation the range was $89.2 \%(95 \%$ CI 87.3 to 91.1 ) to $91.6 \%$ (95\% CI 89.1 to 94.2 ). Adjusted survival in the other regions was 90.3 (95\% CI 88.0 to 92.5) in the South of England and 89.8 (95\% CI 88.0 to 91.8) in the North of England. Only London and the South of England showed improvements in crude survival over 2011 to 2014
(APC: London 1.26\% (95\% CI 0.60 to 1.96); South of England $1.09 \%$ (95\% CI 0.36 to 1.82); Midlands and East of England $0.15 \%$ (95\% CI -0.56 to 0.86 ); North of England 0.26\% (95\% CI -0.54 to 1.07$)$ ). Infants from the most deprived quintile had lower survival rates compared with those from the least deprived quintile $(89.5 \%$ (95\% CI 88.9 to 90.1$)$ vs $91.1 \%(95 \%$ CI 90.2 to 92.1$)$, RD $1.6 \%$ (95\% CI 0.5 to 2.7$)$ ), but no difference remained after standardisation $(89.8 \%$ (95\% CI 87.9 to 91.5 ) vs $90.1 \%$ (95\% CI 87.1 to 93.2 ), RD $0.3 \%$ (95\% CI -3.3 to 3.9)). Inclusion of IMD decile in the risk adjustment model did not change results for each region, with evidence of residual variation across regions $(p<0.001$ from joint test of region indicators).

\section{Survival to discharge from 1995 to 2014 for extremely preterm infants}

We found improvements in survival to discharge of infants born $22^{+0}-25^{+6}$ weeks $^{+ \text {days }}$ to have continued at a similar rate across 1995 (EPICure), 2006 (EPICure 2) and 2008-2014 (NNRD). The EPICure studies found that survival increased from $40 \%$ in 1995 , to $53 \%$ in 2006 , and based on NNRD data, to $66 \%$ (654/992) in 2014. The APC for 1995-2014 was 2.73\% (95\% 


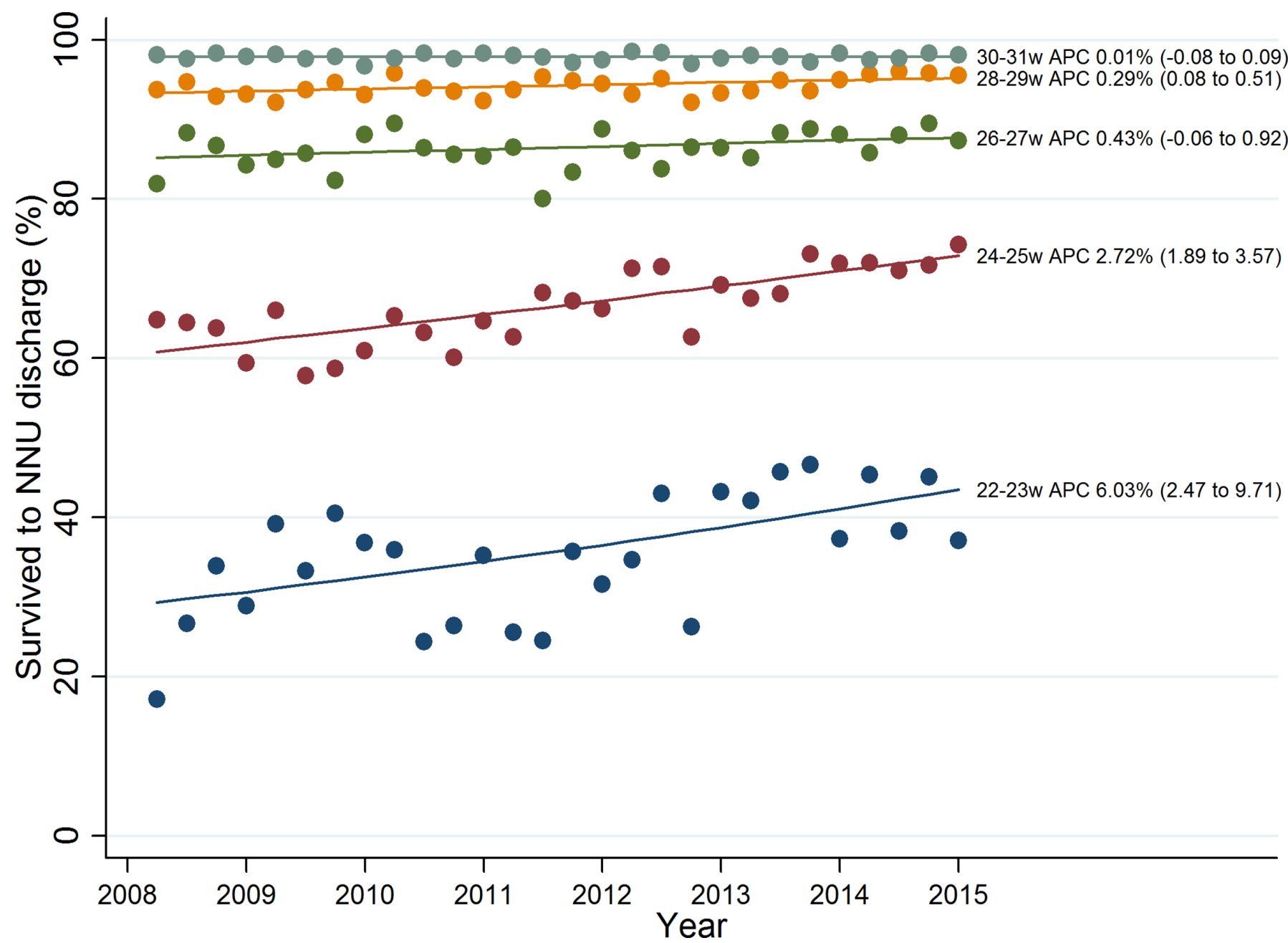

Figure 1 Joinpoint regression analysis for crude rates of survival to discharge for admitted infants born at $22^{+0}-31^{+6}$ weeks' gestation by birth year (2008-2014). APC, average percentage change.

CI 2.35 to 3.12 ), with no evidence for a change in the trend $(\mathrm{p}=0.25)$. Figure 2 shows trends in gestation-specific survival from 1995 to 2014.

\section{Comparison with ONS data}

The number of infants known to have survived to 28 days among admissions of infants born $22^{+0}-31^{+6}$ weeks ${ }^{\text {ddays }} \mathrm{GA}$ recorded in the NNRD for England in 2013 was 6812. This represents $97 \%(6812 / 7027)$ of infants surviving to 28 days recorded by the ONS. There were 538 deaths before 28 days recorded for neonatal admissions in the NNRD, representing $64 \%(538 / 845)$ of deaths among live births in the ONS data. Most of the discrepancy occurred at earlier gestations; there were three survivors and nine deaths among admissions of infants at 22 weeks' GA in the NNRD, compared with 14 survivors and 130 deaths in the ONS (table 3 shows the corresponding numbers for each GA week). The number of NNRD admissions as a percentage of ONS live births of infants $23^{+0}$ $31^{+6}$ weeks $^{+ \text {days }}$ GA was $89 \%$ for the Midlands and East of England, 91\% for London, 89\% for the South of England and $92 \%$ for the North of England in 2013. Table 3 shows corresponding numbers for each GA week; there were no clear patterns indicating regional differences in the proportion of live births admitted to neonatal care.

\section{Predictive model}

Results from the logistic regression model are shown in online supplementary table 1 . The survival predictions are illustrated in online supplementary figures $1-8$. The model predicted well, with an area under the receiver operating characteristic curve of 0.84 (see online supplementary material for further performance statistics).

\section{DISCUSSION}

We identify continuing improvement in the survival of very preterm infants admitted to neonatal care in England, from 1995 to the present, with the greatest increase in the most immature infants. Of note, there is evidence of a north-south divide, and persisting regional variation after adjustment for infant characteristics and socioeconomic differences.

A key strength is that over 50000 very preterm infants were included, representing almost all neonatal admissions in the country during the period. A novel strength is the use of the NNRD, a repository of point-of-care, EPR-derived data, facilitating up-to-date assessment of neonatal outcomes. The estimated survival probabilities, based on near-contemporaneous data, can help guide discussions with parents, noting however the need to emphasise that these relate not to total live births, but to infants admitted to intensive care, and are valuable 


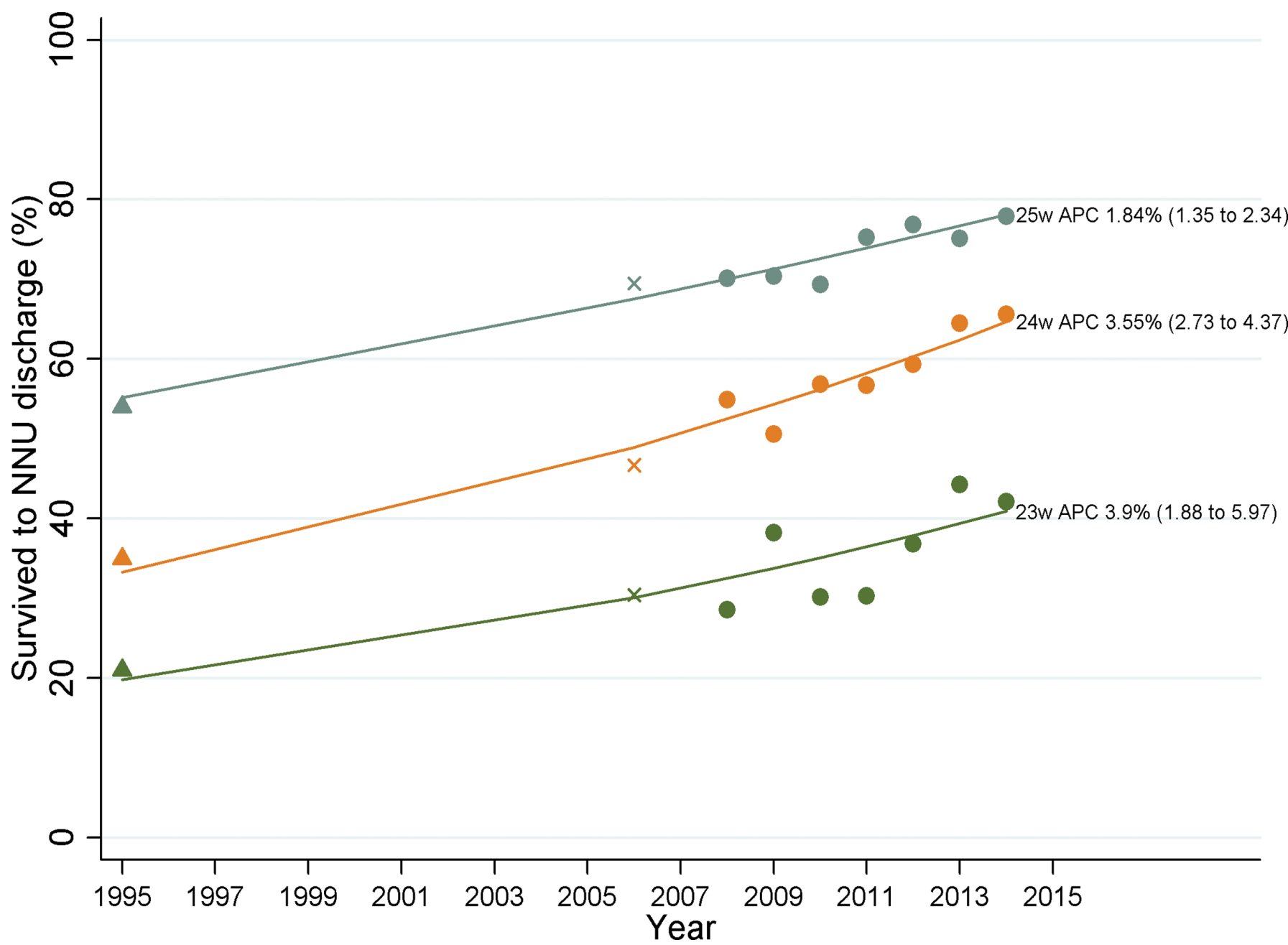

Figure 2 Survival to discharge for infants born 23-25 weeks and admitted to neonatal units in England in 1995 (EPICure; triangle symbol), 2006 (EPICure 2; cross symbol) and 2008-2014 (NNRD; circle symbol). APC, average percentage change; NNRD, National Neonatal Research Database; NNU, neonatal unit.

Table 3 Comparison of NNRD (all admissions to neonatal care among births in England in 2013) and ONS (all live births in England in 2013)

\begin{tabular}{|c|c|c|c|c|c|c|}
\hline & \multicolumn{2}{|l|}{ Survival status* } & \multicolumn{4}{|c|}{ Region of mother's residence* } \\
\hline & Survived to 28 days & Died before 28 days & London & $\begin{array}{l}\text { Midlands and East of } \\
\text { England }\end{array}$ & North of England & South of England \\
\hline Gestational age $\ddagger$ & NNRD/ONS (\%) & NNRD/ONS (\%) & NNRD/ONS (\%) & NNRD/ONS (\%) & NNRD/ONS (\%) & NNRD/ONS (\%) \\
\hline $22^{+0}-22^{+6}$ & $3 / 14(21)$ & $9 / 130(7)$ & $t$ & $t$ & $t$ & + \\
\hline $23^{+0}-23^{+6}$ & 105/104 (101) & $81 / 168(48)$ & 44/57 (77) & $52 / 77(68)$ & $51 / 79(65)$ & $31 / 57(54)$ \\
\hline $24^{+0}-24^{+6}$ & $274 / 298(92)$ & 109/158 (69) & 79/108 (73) & $93 / 109(85)$ & $110 / 134(82)$ & $80 / 105(76)$ \\
\hline $27^{+0}-27^{+6}$ & 619/646 (96) & 49/54 (91) & $115 / 130(88)$ & $184 / 202(91)$ & 194/199 (97) & 144/164 (88) \\
\hline $28^{+0}-28^{+6}$ & $852 / 865(98)$ & $59 / 60(98)$ & 173/192 (90) & $248 / 268(93)$ & $221 / 242(91)$ & 208/221 (94) \\
\hline $29^{+0}-29^{+6}$ & 1049/1069 (98) & 34/41 (83) & 194/198 (98) & $300 / 334(90)$ & $311 / 342(91)$ & $221 / 236(94)$ \\
\hline $30^{+0}-30^{+6}$ & $1306 / 1351$ (97) & $28 / 32(88)$ & 247/261 (95) & $371 / 412(90)$ & $371 / 384(97)$ & 275/324 (85) \\
\hline $31^{+0}-31^{+6}$ & 1723/1766 (98) & $27 / 39(69)$ & 349/376 (93) & 449/496 (91) & 462/491 (94) & 405/436 (93) \\
\hline
\end{tabular}

* There were 17 infants in the NNRD with unknown survival status and 389 with unknown region of mother's residence so row totals may not correspond.

tLive births at 22 weeks' gestational age by region was not published.

¥There were 2256 live births in ONS data where gestational age data could not be linked or were not recorded.

NNRD, National Neonatal Research Database; ONS, Office of National Statistics. 
information for clinicians, managers and commissioners. Validation of the prediction model using a future cohort would confirm its applicability; such a cohort can be easily established from new admissions in the NNRD. The risk adjustment variables were important, unambiguous clinical characteristics, also obtained from the NNRD. We took several steps to limit or investigate potential bias and conclusions remained valid following a number of sensitivity analyses. Around 3.4\% of infants had missing outcome data, which could bias the assessment of survival trends. Outcomes were missing due to transfer to a neonatal unit or specialist surgical provider not contributing data to the NNRD. While the number of neonatal units contributing increased over time, sensitivity analysis including only providers contributing data throughout the period yielded similar results. A limitation is that live-born infants who died before admission to neonatal care were not included. This is illustrated by the lower number of deaths of admitted infants recorded in the NNRD compared with deaths among live births in the ONS, largely at the earliest gestations. This limitation was unavoidable as data capture is triggered by neonatal unit admission. Changes in survival of admitted infants could result from changes in admission practices over time. Although such changes could not be ascertained from the data available, trends persisted after adjustment for key risk factors. However the similarity with ONS data for the number of infants surviving to 28 days provides reassurance on population completeness for admitted infants. Regional variation could be attributable to differences in criteria for active management of extremely preterm infants. If the southern regions have higher survival because the sickest infants are less likely to be admitted for active care, we would expect a lower proportion of live births to be admitted in these regions. Comparison of regional ONS and NNRD data showed no such pattern, although regional ONS data on infants born at 22 weeks' GA were unavailable.

Our study covers the entire population of neonatal admissions in a geographically defined region. This contrasts with previous reports such as those from the US National Institute of Child Health and Human Development Neonatal Research Network that focus on admissions to tertiary neonatal units, ${ }^{16} 17$ a bias that may predispose to exaggerated estimates of survival. Nonetheless, survival rates were similar; in our study survival to discharge for infants at 24 weeks in 2014 was $66 \%$, compared with the $65 \%$ survival in 2012 reported in a US tertiary neonatal unit admission study. ${ }^{16}$ This survival rate was also similar to the $59 \%$ found in a population-based regional study of admitted infants born over 2007-2011 in Australia. ${ }^{18}$ In contrast in 2011, the French EPIPAGE-2 study including all live births showed 31\% survival to discharge. ${ }^{19}$ However it should be noted that inclusion of all live births does not guarantee a consistent population, as shown by the variation across England in whether infants less than 24 weeks who die shortly after birth are in fact registered as live births. ${ }^{20}$

Our study has several implications for clinicians, policy makers and researchers. First, although not evidenced by published data to date, continued improvement in survival of very preterm infants may lead in future to a growing number of children and adults with long-term health needs. Opportunity for cost-effective long-term ascertainment of outcomes for all infants admitted to neonatal care is offered by linkage of NNRD data with other national records, such as hospital, general practice and educational data sets. Second, the improvement in survival appears to be largely at lower GA and was inconsistent across the regions. Identifying and reducing inequity in health outcomes are a stated intention of the UK Government and NHS England. Third, we show that NNRD data, derived from EPR, enable timely evaluations of outcomes and eliminate the need for separate data capture by busy clinical teams. The small number of very preterm births and the increasing rarity of death in this population mean that large sample sizes enabled by the national coverage of the NNRD are required to detect variation. There is considerable interest in using EPR for research; we hope our study will serve as a template to advance this approach to improve patient care.

Acknowledgements The authors would like to thank all infants and families whose data contribute to the NNRD. We acknowledge the invaluable assistance of Richard Colquhoun, Buthaina Ibrahim and clinical teams from all contributing neonatal units (listed below with the current lead clinician for each unit). Airedale General Hospital (Dr Matthew Babirecki), Alexandra Hospital (Dr Liza Harry), Arrowe Park Hospital (Dr Oliver Rackham), Barnet Hospital (Dr Tim Wickham), Barnsley District General Hospital (Dr Sanaa Hamdan), Basildon Hospital (Dr Aashish Gupta), Basingstoke \& North Hampshire Hospital (Dr Ruth Wigfield), Bassetlaw District General Hospital (Dr L M Wong), Bedford Hospital (Dr Anita Mittal), Birmingham City Hospital (Dr Julie Nycyk), Birmingham Heartlands Hospital (Dr Phil Simmons), Birmingham Women's Hospital (Dr Anju Singh), Bradford Royal Infirmary (Dr Sunita Seal), Broomfield Hospital, Chelmsford (Dr Ahmed Hassan), Calderdale Royal Hospital (Dr Karin Schwarz), Chelsea \& Westminster Hospital (Dr Mark Thomas), Chesterfield \& North Derbyshire Royal Hospital (Dr Aiwyne Foo), Colchester General Hospital (Dr Aravind Shastri), Conquest Hospital (Dr Graham Whincup), Countess of Chester Hospital (Dr Stephen Brearey), Croydon University Hospital (Dr John Chang), Cumberland Infirmary (Dr Khairy Gad), Darent Valley Hospital (Dr Abdul Hasib), Darlington Memorial Hospital (Dr Mehdi Garbash), Derriford Hospital (Dr Alex Allwood), Diana Princess of Wales Hospital (Dr Pauline Adiotomre), Doncaster Royal Infirmary (Dr Jamal S Ahmed), Dorset County Hospital (Dr Abby Deketelaere), East Surrey Hospital (Dr K Abdul Khader), Epsom General Hospital (Dr Ruth Shephard), Frimley Park Hospital (Dr Abdus Mallik), Furness General Hospital (Dr Belal Abuzgia), George Eliot Hospital (Dr Mukta Jain), Gloucester Royal Hospital (Dr Simon Pirie), Good Hope Hospital (Dr Phil Simmons), Great Western Hospital (Dr Stanley Zengeya), Guy's \& St Thomas' Hospital (Dr Timothy Watts), Harrogate District Hospital (Dr C Jampala), Hereford County Hospital (Dr Cath Seagrave), Hillingdon Hospital (Dr Michele Cruwys), Hinchingbrooke Hospital (Dr Hilary Dixon), Homerton Hospital (Dr Narendra Aladangady), Hull Royal Infirmary (Dr Hassan Gaili), Ipswich Hospital (Dr Matthew James), James Cook University Hospital (Dr M Lal), James Paget Hospital (Dr Ambadkar), Kettering General Hospital (Dr Patty Rao), Kings College Hospital (Dr Ann Hickey), King's Mill Hospital (Dr Dhaval Dave), Kingston Hospital (Dr Vinay Pai), Lancashire Women and Newborn Centre (Dr Meera Lama), Leeds Neonatal Service (Dr Lawrence Miall), Leicester General Hospital (Dr Jonathan Cusack), Leicester Royal Infirmary (Dr Venkatesh Kairamkonda), Leighton Hospital (Dr Jayachandran), Lincoln County Hospital (Dr Kollipara), Lister Hospital (Dr J Kefas), Liverpool Women's Hospital (Dr Bill Yoxall), Luton \& Dunstable Hospital (Dr Jennifer Birch), Macclesfield District General Hospital (Dr Gail Whitehead), Manor Hospital (Dr Krishnamurthy), Medway Maritime Hospital (Dr Aung Soe), Milton Keynes General Hospital (Dr I Misra), New Cross Hospital (Dr Tilly Pillay), Newham General Hospital (Dr Imdad Ali), Norfolk \& Norwich University Hospital (Dr Mark Dyke), North Devon District Hospital (Dr Michael Selter), North Manchester General Hospital (Dr Nagesh Panasa), North Middlesex University Hospital (Dr Lesley Alsford), North Tyneside General Hospital (Dr Vivien Spencer), Northampton General Hospital (Dr Subodh Gupta), Northwick Park Hospital (Dr Richard Nicholl), Nottingham City Hospital (Dr Steven Wardle), Nottingham University Hospital (QMC) (Dr Steven Wardle), Ormskirk District General Hospital (Dr Tim McBride), Oxford University Hospitals, Horton Hospital (Dr Naveen Shettihalli), Oxford University Hospitals, John Radcliffe Hospital (Dr Eleri Adams), Peterborough City Hospital (Dr Seif Babiker), Pilgrim Hospital (Dr Margaret Crawford), Pinderfields General Hospital (Pontefract General Infirmary) (Dr David Gibson), Poole General Hospital (Prof Minesh Khashu), Princess Alexandra Hospital (Dr Caitlin Toh), Princess Anne Hospital (Dr Mike Hall), Princess Royal Hospital (Dr P Amess), Princess Royal University Hospital (Dr Elizabeth Sleight), Queen Alexandra Hospital (Dr Charlotte Groves), Queen Charlotte's Hospital (Dr Sunit Godambe), Queen Elizabeth Hospital, Gateshead (Dr Dennis Bosman), Queen Elizabeth Hospital, King's Lynn (Dr Glynis Rewitzky), Queen Elizabeth Hospital, Woolwich (Dr Olutoyin Banjoko), Queen Elizabeth the Queen Mother Hospital (Dr N Kumar), Queen's Hospital, Burton on Trent (Dr Azhar Manzoor), Queen's Hospital, Romford (Dr Wilson Lopez), Rosie Maternity Hospital, Addenbrookes (Dr Angela D'Amore), Rotherham District General Hospital (Dr Shameel Mattara), Royal Albert Edward Infirmary (Dr Christos Zipitis), Royal Berkshire Hospital (Dr Peter De Halpert), Royal Bolton Hospital (Dr Paul Settle), Royal Cornwall Hospital (Dr Paul Munyard), Royal Derby Hospital (Dr John Mclntyre), Royal Devon \& Exeter Hospital (Dr David Bartle), Roya Hampshire County Hospital (Dr Katie Yallop), Royal Lancaster Infirmary (Dr Joanne Fedee), Royal Oldham Hospital (Dr Natasha Maddock), Royal Preston Hospital (Dr Richa Gupta), Royal Shrewsbury Hospital (Dr Deshpande), Royal Stoke University Hospital (Dr Alison Moore), Royal Surrey County Hospital (Dr Charles Godden), Royal Sussex County Hospital (Dr P Amess), Royal United Hospital (Dr Stephen Jones), 
Royal Victoria Infirmary (Dr Alan Fenton), Russells Hall Hospital (Dr Mahadevan), Salisbury District Hospital (Dr Nick Brown), Scarborough General Hospital (Dr Kirsten Mack), Scunthorpe General Hospital (Dr Pauline Adiotomre), South Tyneside District Hospital (Dr Rob Bolton), Southend Hospital (Dr Arfa Khan), Southmead Hospital (Dr Paul Mannix), St George's Hospital (Dr Charlotte Huddy), St Helier Hospital (Dr Salim Yasin), St Mary's Hospital, Isle of Wight (Dr Sian Butterworth), St Mary's Hospital, London (Dr Sunit Godambe), St Mary's Hospital, Manchester (Dr Ngozi Edi-Osagie), St Michael's Hospital (Dr Pamela Cairns), St Peter's Hospital (Dr Peter Reynolds), St Richard's Hospital (Dr Nick Brennan), Stepping Hill Hospital (Dr Carrie Heal), Stoke Mandeville Hospital (Dr Sanjay Salgia), Sunderland Royal Hospital (Dr Majd Abu-Harb), Tameside General Hospital (Dr Jacqeline Birch), Taunton \& Somerset Hospital (Dr Chris Knight), The Jessop Wing, Sheffield (Dr Simon Clark), The Royal Free Hospital (Dr V Van Sommen), The Royal London Hospital - Constance Green (Dr Vadivelam Murthy), Torbay Hospital (Dr Siba Paul), Tunbridge Wells Hospital (Dr Hamudi Kisat), University College Hospital (Dr Giles Kendall), University Hospital Coventry (Dr Kate Blake), University Hospital Lewisham (Dr Jauro Kuna), University Hospital of North Durham (Dr Mehdi Garbash), University Hospital of North Tees (Dr Hari Kumar), University Hospital of South Manchester (Dr Gopi Vemuri), Victoria Hospital, Blackpool (Dr Chris Rawlingson), Warrington Hospital (Dr Delyth Webb), Warwick Hospital (Dr Bird), Watford General Hospital (Dr Sankara Narayanan), West Cumberland Hospital (Dr Jason Gane), West Middlesex University Hospital (Dr Elizabeth Eyre), West Suffolk Hospital (Dr lan Evans), Wexham Park Hospital (Dr Rekha Sanghavi), Whipps Cross University Hospital (Dr Caroline Sullivan), Whiston Hospital (Dr Laweh Amegavie), Whittington Hospital (Dr Wynne Leith), William Harvey Hospital (Dr Vimal Vasu), Worcestershire Royal Hospital (Dr Andrew Gallagher), Worthing Hospital (Dr Katia Vamvakiti), Yeovil District Hospital (Dr Megan Eaton), York District Hospital (Dr Guy Millman).

Collaborators *Members of the Medicines for Neonates Investigator Group: Neena Modi, ${ }^{1}$ Jane Abbott, ${ }^{2}$ Deborah Ashby, ${ }^{3}$ Peter Brocklehurst, ${ }^{4}$ Kate Costeloe, ${ }^{5}$ Elizabeth Draper, ${ }^{6}$ Jacquie Kemp ${ }^{7}$ Azeem Majeed ${ }^{8}$ Stavros Petrou, ${ }^{9}$ Alys Young ${ }^{10}$. ${ }^{1}$ Neonatal Data Analysis Unit, Section of Neonatal Medicine, Department of Medicine, Imperial College London, Chelsea and Westminster Hospital campus, 369 Fulham Road, London SW10 9NH, UK. ${ }^{2}$ Bliss, 2nd Floor, Chapter House, 18C20 Crucifix Lane, London SE1 3JW, UK. ${ }^{3}$ Imperial Clinical Trials Unit, 1st Floor, Stadium House, 68 Wood Lane, London W12 7RH, UK. ${ }^{4}$ UCL EGA Institute for Women's Health, Medical School Building, 74 Huntley Street, London WC1E 6AU, UK. ${ }^{5}$ Blizard Institute, Barts and the London School of Medicine and Dentistry, 4 Newark Street, London E12AT, UK. ${ }^{6}$ Department of Health Sciences, University of Leicester, Centre for Medicine, University Road, Leicester LE1 7RH, UK. ${ }^{7}$ London Specialised Commissioning Group, London, UK. ${ }^{8}$ Department of Primary Care and Public Health, School of Public Health, Faculty of Medicine, Imperial College London, Charing Cross campus, Reynolds Building, St Dunstans Road, London W6 8RP, UK. ${ }^{9}$ Division of Health Sciences, Warwick Medical School, University of Warwick, Coventry CV4 7AL, UK. ${ }^{10}$ Manchester Academic Health Sciences Centre, Core Technology Facility, The University of Manchester, 46 Grafton Street, Manchester M13 9NT, UK.

Contributors All authors contributed to study design and analysis. SS and NM are the guarantors for the study. SS, YS, DG, CB and NM had full access to the NNRD data. All authors had full access to the summary data presented in this paper (including statistical reports and tables) in the study and can take responsibility for the integrity of the data and the accuracy of the data analysis.

Funding SS, YS and CB were funded by the National Institute for Health Research under its Programme Grants for Applied Research Programme (Grant Reference Number RP-PG-0707-10010) held by NM. DG receives salary support through the Royal College of Paediatrics and Child Health National Neonatal Audit Programme that is commissioned by the Healthcare Quality Improvement Partnership and funded by the Department of Health. The views expressed are those of the authors and not necessarily those of the NHS, the NIHR, the RCPCH, or the Department of Health. Neither the study sponsor, Imperial College London, nor the study funder, the National Institute for Health Research, had any role in in the collection, analysis, and interpretation of data; in the writing of the report; and in the decision to submit the article for publication.

Ethics approval National Research Ethics Service (16/L0/1093).

Provenance and peer review Not commissioned; externally peer reviewed.
Data sharing statement Data from this study are available for prespecified purposes subject to approval from the Neonatal Data Analysis Unit Steering Board.

Open Access This is an Open Access article distributed in accordance with the terms of the Creative Commons Attribution (CC BY 4.0) license, which permits others to distribute, remix, adapt and build upon this work, for commercial use, provided the original work is properly cited. See: http://creativecommons.org/licenses/by/4.0/

(c) Article author(s) (or their employer(s) unless otherwise stated in the text of the article) 2018. All rights reserved. No commercial use is permitted unless otherwise expressly granted.

\section{REFERENCES}

1 Lawn JE, Cousens S. Zupan J for the Lancet Neonatal Survival Steering Team. 4 million neonatal deaths: when? where? why? Lancet 2005;365:891-900.

2 Saigal S, Doyle LW. An overview of mortality and sequelae of preterm birth from infancy to adulthood. Lancet 2008;371:261-9.

3 Marlow N. Keeping up with outcomes for infants born at extremely low gestational ages. JAMA Pediatr 2015;169:207-8.

4 Gale C, Morris I. Neonatal Data Analysis Unit (NDAU) Steering Board. The UK National Neonatal Research Database: using neonatal data for research, quality improvement and more. Arch Dis Child Educ Pract Ed 2016;101:216-8.

5 Department for Communities and Local Government. The English Indices of Deprivation 2010, Technical report, Department of Communities and Local Governement. London, 2011. https://www.gov.uk/government/statistics/englishindices-of-deprivation-2010.

6 Scientific Advisory Committee on Nutrition (SACN). Application of WHO growth standards in the UK 2007. London: Stationery Office. 2008.

7 Joinpoint v4.2.0. Statistical methodology and applications Branch, Surveillance Research Program. National Cancer Institute.

$8 \mathrm{Kim} \mathrm{HJ}$, Fay MP, Feuer EJ, et al. Permutation tests for joinpoint regression with applications to Cancer rates. Stat Med 2000;19:335-51.

9 Nicholl J, Jacques RM, Campbell MJ. Direct risk standardisation: a new method for comparing casemix adjusted event rates using complex models. BMC Med Res Methodol 2013;13:133

10 Fay MP, Feuer EJ. Confidence intervals for directly standardized rates: a method based on the gamma distribution. Stat Med 1997;16:791-801.

11 Medlock S, Ravelli AC, Tamminga P, et al. Prediction of mortality in very premature infants: a systematic review of prediction models. PLoS One 2011;6:e23441.

12 Costeloe K, Hennessy E, Gibson AT, et al. The EPICure study: outcomes to discharge from hospital for infants born at the threshold of viability. Pediatrics 2000;106:659-71.

13 Costeloe KL, Hennessy EM, Haider S, et al. Short term outcomes after extreme preterm birth in England: comparison of two birth cohorts in 1995 and 2006 (the EPICure studies). BMJ 2012;345:e7976

14 Office of National Statistics. Gestation-specific infant mortality in England, 2013 tables 2016 http://www.ons.gov.uk/ons/rel/child-health/gestation-specific-infantmortality-in-england-and-wales/2013/rft-gestation-specific-infant-mortality-2013reference-tables.xls

15 Live events and Population sources Division, Office of National Statistics Births and infant mortality rates by gestation, England. http://www.ons.gov.uk/peoplepopulatio nandcommunity/birthsdeathsandmarriages/livebirths/adhocs/005290tablesonbirthsan dinfantdeathsbygestationenglandonly (accessed 30 Nov 2016).

16 Stoll BJ, Hansen NI, Bell EF, et al. For the Eunice Kennedy Shriver NICHD Neonatal Research Network. trends in Care Practices, morbidity, and mortality of extremely preterm neonates, 1993-2012. JAMA 2015;314:1039-51.

17 Patel RM, Kandefer S, Walsh MC, et al. For the Eunice Kennedy Shriver NICHD Neonatal Research Network. causes and timing of death in extremely premature infants from 2000 through 2011. N Engl J Med 2015;372:331-40.

18 Bolisetty S, Legge N, Bajuk B. Lui K for the NSW and ACT Neonatal Intensive Care Units' Data Collection. preterm infant outcomes in New South Wales and the Australian Capital Territory. J Paediatr Child Health 2015;51:713-21.

19 Ancel PY, Goffinet F for the EPIPAGE-2 Writing Group. Survival and morbidity of Preterm Children Born at 22 through 34 weeks' Gestation in France in 2011: results of the EPIPAGE-2 Cohort Study. JAMA Pediatr 2015;169:230-8.

20 Smith L, Draper ES, Manktelow BN, et al. Comparing regional infant death rates: the influence of preterm births $<24$ weeks of gestation. Arch Dis Child Fetal Neonatal Ed 2013;98:F103-7. 